\title{
Scientific evidence for the control of antimicrobial resistance
}

\author{
Celia Mercedes Alpuche Aranda1, Cesar A. Arias², Carlos Espinal Tejada ${ }^{3}$, Corey Forde ${ }^{4}$, Benjamin \\ Park $^{5}$, Flavia Rossi ${ }^{6}$ and Monica Thormann ${ }^{7}$
}

Suggested citation Alpuche Aranda CM, Arias CA, Espinal Tejada C, Forde C, Park B, Rossi F et al. Scientific evidence for the control of antimicrobial resistance. Rev Panam Salud Publica. 2020;44:e128 https://doi.org/10.26633/RPSP.2020.128

Antimicrobial resistance (AMR) is one of the greatest global threats to human health. It is estimated that by 2050, AMR will lead to approximately 10 million annual deaths worldwide (1). Considering the impact of AMR on reproductive capacity and food production, in addition to its direct effect on infected people, the world's population could drop by between 11 and 444 million inhabitants by 2050 if AMR control is not achieved (2).

As migrations and shared economies lead to the transmission of resistant bacteria across borders, the impacts of AMR become regionally significant. In the United States, methicillin-resistant Staphylococcus aureus caused 10600 deaths in 2017 (2). In Latin American and Caribbean countries, information is available from studies conducted in hospitals and other health facilities on the prevalence of antimicrobial-resistant pathogens. In many hospitals in Mexico, Peru, and Colombia, for example, resistance to third-generation cephalosporins and fluoroquinolones in Escherichia coli isolates is reaching almost $60 \%(3,4)$. Moreover, the dynamics of colonization and infection of multidrug-resistant organisms (such as carbapenemaseproducing Klebsiella pneumoniae) are unique in endemic areas of Latin America, favoring spread and dissemination $(5,6)$.

Observational studies estimate approximately 50\% misuse of antibiotics by health care providers in the Region of the Americas (7), and $20-40 \%$ self-medication by patients $(7,8)$. However, there are no regional studies on the use of antimicrobials in hospitals. Accordingly, there is an urgent need to advance current knowledge on the prescription and use of antimicrobials, both in the community and during acute care in hospital settings.

Aside from its implications for human health, AMR has major consequences for countries' socioeconomic development.
In its 2017 report, the World Bank estimated that annual gross domestic product will fall between $1.1 \%$ and $3.8 \%$ by 2050 in countries with low- and high-impact AMR scenarios, respectively, and by $5 \%$ or more in low-income countries with high-impact scenarios. It is estimated that extreme poverty will increase by 28.3 million people, 26.2 million of whom will be in low-income countries (9). By 2050, the cost of health care will increase from $\$ 300$ billion to $\$ 1$ trillion annually (9).

AMR prevention and control requires integrated and multisectoral strategies such us decrease the use of antimicrobials both in human health and veterinary / animal husbandry, ensure hygiene practices and vaccination to reduce the spread of infectious diseases, and harmonize norms and regulations on antimicrobial use and sales, to advance the implementation and impact of national programs. Countries must be seriously committed and take concrete actions in different areas of their programs to achieve the proposed objectives and reduce the negative impact of AMR on the population, health systems, and the economy. These strategies and programs should also consider the COVID-19 pandemic, which could increase the irrational use of over-the-counter antibiotics, antimalarials, and antiparasitic drugs in the community, as observed in some countries with therapies that are not proven such as azithromycin, hydroxychloroquine, and ivermectin. At the hospital level, we must estimate the impact of COVID-19 on stewardship programs that promote the rational use of antibiotics.

Academia, including universities and health and agriculture institutions, plays a very important role in conducting research and proposing interventions that governments can adopt as part of their AMR control strategies. Rational use of antibiotics

\footnotetext{
National Public Health Institute, Mexico City, Mexico

2 The University of Texas Health Science Center at Houston, Houston, United States of America and Universidad El Bosque, Bogotá, Colombia

3 Global Health Consortium, Robert Stempel College of Public Health \& Social Work, Florida International University, Miami, United States of America

4 Queen Elizabeth Hospital, Bridgetown, Barbados
}

\footnotetext{
5 Division of Healthcare Quality Promotion, US Centers for Disease Control and Prevention, Atlanta, United States of America

6 Hospital das Clínicas da Faculdade de Medicina da Universidade de São Paulo, São Paulo, Brazil

7 Pan American Association of Infectious Diseases, Santo Domingo, Dominican Republic
} 
requires precise guidance to support program implementation in hospitals. In 2018, a collaborative effort between the Pan American Health Organization (PAHO) and the Global Health Consortium (Robert Stempel College of Public Health and Social Work, Florida International University) published Recommendations for Implementing Antimicrobial Stewardship Programs in Latin America and the Caribbean. The publication summarizes key components for implementing these programs, from the necessary profiles and competencies of human resources to normative and financial aspects, with an emphasis on monitoring antimicrobial use (10).
Because AMR is a dynamic and changing topic not limited to any one country, it is essential to produce and disseminate new scientific evidence. This special issue of the Pan American Journal of Public Health dedicated to antimicrobial resistance is a joint effort between PAHO and the Global Health Consortium. It presents a select number of scientific studies carried out in the Region of the Americas; seeks to encourage scientific production on relevant aspects of epidemiology, disease control, and public policies on antimicrobial resistance; and highlights successful interventions as examples of good practices for the countries of the Region.

\section{REFERENCES}

1. O`Neill J. (Ed.). Tackling drug-resistant infections globally: final report and recommendations. the review on antimicrobial resistance. London: Wellcome Trust, HM Government; 2016. Available from: https: / / amr-review.org/sites / default/files/160518_Final\%20 paper_with\%20cover.pdf

2. US Centers for Disease Control. Biggest threats and data. Available from: https://www.cdc.gov/drugresistance/biggest-threats.html\# mrsa

3. Cox JA, Vlieghe E, Mendelson M, Wertheim H, Ndegwa L, Villegas $\mathrm{MV}$, et al. Antibiotic stewardship in low- and middle-income countries: the same but different? Clin Microbiol Infect. 2017;23:812-818.

4. Levy Hara G. Recopilación y análisis de los estudios de resistencia antimicrobiana para el diagnóstico de la situación y elaboración del plan de acción para contener la resistencia antimicrobiana en la subregión andina, 2015. [Consultancy report in Spanish]. Available from: http://www.orasconhu.org/sites/default/files/ Consultor $\%$ C3\%ADa $\% 20$ LEVI\%20completo $\% 20$ consolidado $\% 20$ definitivo $\% 2023 \% 20$ diciembre.pdf.

5. Rada AM, Cadena E, Agudelo C, Capataz C, Orozco N, Pallares $\mathrm{C}$ et al. Dynamics of bla $\mathrm{KPC}-2_{2}$ dissemination from non-CG258 Klebsiella pneumoniae to other Enterobacterales via IncN plasmids in an area of high endemicity. Antimicrob Agents Chemother. 2020 Sep 21:AAC.01743-20. doi: 10.1128/AAC.01743-20

6. Rojas LJ, Weinstock GM, Cadena E, Diaz L, Rios R, Hanson BM et al. J Infect Dis. 2017 Dec 27;217(1):82-92 doi: 10.1093/infdis/jix524

7. Castro JL, Levy Hara G, Muñoz S, Silveira de Castro M, Berrios ME, Montenegro A, et al. Consumo de antibióticos en Nicaragua y Honduras. Análisis de aspectos metodológicos y principales resultados. Rev Panam Infectol. 2008;10(Supl 1):s104-s111.

8. Center for Disease Dynamics, Economics \& Policy. State of the world's antibiotics, 2015. Washington, DC: CDDEP; 2015. Available from: https://cddep.org/publications/state_worlds_antibiotics_2015/.

9. The World Bank. Final report. Drug-resistant infections. A threat to our economic future. Washington, DC: The World Bank; 2017. Available from: http://documents.worldbank.org/curated/en/3233114 93396993758 / pdf / 114679-REVISED-v2-Drug-Resistant -Infections-Final-Report.pdf.

10. Pan American Health Organization. Florida International University. Recommendations for Implementing Antimicrobial Stewardship Programs in Latin America and the Caribbean: Manual for Public Health Decision-Makers. Washington, DC: PAHO, FIU; 2018. Available from: https://iris.paho.org/handle/10665.2/49645

\section{Appreciation}

The Journal appreciates the support of the Editorial Board, authors of this Editorial, during the planning of the special issue and the selection of articles. Their contributions helped make the manuscripts more interesting, more accurate, and more useful to our readers and all others who work to improve the health of the peoples of the Americas.
The Journal acknowledges the contribution of the Global Health Consortium (Robert Stempel College of Public Health and Social Work, Florida International University) for its financial and programmatic support during the production of this special issue. 